\title{
Extensive epidural fluid collections: does it influence the outcome?
}

\section{Coleções exuberantes de líquor epidural: influência na resposta ao tratamento?}

Sara França ${ }^{1}$, Ana Teresa Carvalho ${ }^{1}$, Joana Guimarães ${ }^{1}$, Rita Figueiredo², Carina Reis², Maria Armanda Gomes ${ }^{3}$

A 32-year-old woman presented with a three-day history of orthostatic headache. Brain CT and MRI were normal. Hole-spine MR mielography and conventional Spine MRI disclosed exuberant enlargement of posterior epidural space and images suggestive of cervical CSF leak (Fig 1). CT myelography confirmed CSF leak. It was performed conservative treatment without symptom relief. Clinical improvement was only evident after third epidural blood patch. Five months later, she remained asymptomatic despite mantaining exuberant collections, not supporting a correlation between imagiological and clinical improvement (Fig 2). Another question that remains to be solved is whether the extent of the collections of CSF influences the outcome ${ }^{1}$.

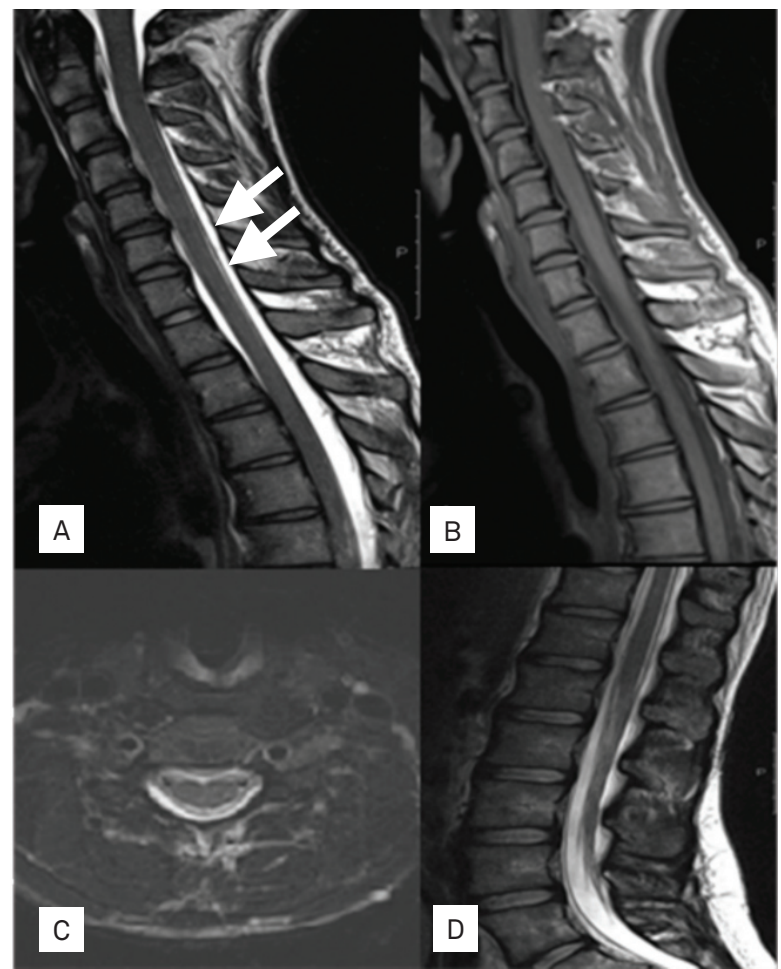

Fig 1. Spinal MRI - hyperintense sign on T2 sequences (A, C, D) with no corresponding hyperintense sign on T1 (B), suggesting not fat tissue but large collections of CSF into the epidural space that extends from cervical (C3) to the lumbar segments (L1-L2). Upper arrow: dura mater; lower arrow: extended epidural space.

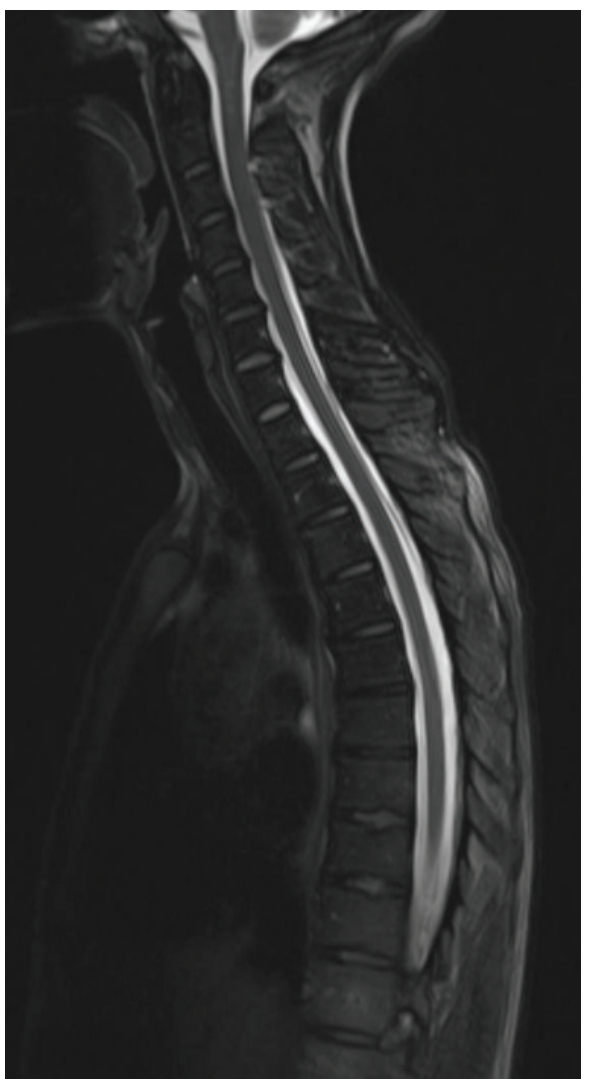

Fig 2. Spinal MRI five months after epidural blood patch, revealing no imagiological improvement.

\section{References}

Inamasu J, Nakatsukasa M. Blood patch for spontaneous intracranial hypotension caused by cerebrospinal fluid leak at C1-2. Clin Neurol Neurosurg 2007;109:716-719.

\footnotetext{
Centro Hospitalar de São João, Porto - Portugal:

${ }^{1}$ Neurology Department;

${ }^{2}$ Neuroradiology Department;

${ }^{3}$ Anesthesiology Department.
}

Correspondence: Sara França; Alameda Professor Hernâni Monteiro 4202/451; Porto - Portugal; E-mail: sarafranca5@hotmail.com Conflict of interest: There is no conflict of interest to declare.

Received 14 December 2011; Accepted 28 December 2011 